\title{
PERAN SERTA SUAMI DAN PERILAKU IBU HAMIL DALAM PERAWATAN KEHAMILAN DI PUSKESMAS WIROSARI I
}

\author{
Rosmala Kurnia Dewi ${ }^{1}$, Pintam Ayu Yastirin²) \\ 1) Fakultas Sains \& Kesehatan, Universitas An Nuur \\ E-mail : kurniadewirosmala@annurpurwodadi.ac.id \\ 2) Fakultas Sains \& Kesehatan, Universitas An Nuur
}

\begin{abstract}
ABSTRAK
Angka Kematian Ibu (AKI) di Indonesia masih menjadi tren permasalahan kesehatan, dimana berdasarkan data SUPAS 2015 AKI berkisar 305/100.000 kelahiran hidup. Angka tersebut mengalami penurunan jika dibandingka AKI tahun 2010 sebesar 346/100.000 kelahiran hidup. Akan tetapi AKI tahun 2015 di Indonesia masih jauh dari target MDGs, yang mentargetkan AKI pada kisaran angka 102/100.000 kelahiran hidup. Banyaknya faktor yang terkait tentang kematian ibu di Indonesia diantaranya kualitas perilaku ibu hamil yang tidak memanfaatkan ANC. Salah satu kegiatan dalam pelayanan antenatal terpadu dengan melibatkan ibu hamil, suami dan keluarga untuk menjaga kesehatan dan gizi ibu hamil, menyiapkan persalinan dan kesiagaan apabila terjadi penyulit/komplikasi. Tujuan penelitian ini untuk mendeskripsikan bagaimana peran serta suami dalam perawatan kehamilan yang diambil lokasi penelitian di Puskesmas Wirosari 1. Penelitian ini menggunakan metode survei deskriptif, dimana peneliti akan mendeskripsikan peran suami dalam perawatan kehamilan. sampel yang diteliti diambil menggunakan teknik random sampling sejumlah 184 ibu hamil. Penelitian dilaksanakan pada bulan Desember 2018 - Juli 2019. Data penelitian dikumpulkan menggunakan metode wawancara terpimpin, yang selanjutnya akan diolah menggunakan analisis univariat. Karakteristik responden dilihat dari usia, pendidikan dan paritas. Sebagian besar responden kelompok usia 21-35 tahun sebanyak 167 responden (91\%), dengan pendidikan terakhir mayoritas tamat SMA sebanyak 60 responden (33\%) dan berdasarkan paritas mayoritas multigravida sebanyak 136 responden (74\%). Dari hasil penelitian peran suami dalam perawatan kehamilan mayoritas mendukung ibu hamil melakukan perawatan kehamilan sebanyak 157 responden $(85,3 \%)$ dan mayoritas ibu hamil melakukan perawatan kehamilan sebanyak 181 responden $(98,4 \%)$. Dengan adanya dukungan suami pada ibu hamil dalam melakukan perawatan kehamilan, maka ibu akan tepat waktu dalam melakukan perawatan kehamilan, dengan adanya tepat waktu dalam melakukan perawatan kehamilan ataupun kunjungan antenatal care maka akan mempermudah tenaga kesahatan mendeteksi komplikasi kehamilan secara dini.
\end{abstract}

\section{Kata Kunci : Peran Suami, Perilaku Ibu Hamil Dalam Perawatan Kehamilan}

\section{ABSTRACT}

Maternal Mortality Rate (MMR) in Indonesia is still a trend of health problems, where based on SUPAS 2015 data AKI ranges from $305 / 100,000$ live births. This figure has decreased if compared to the MMR in 2010 amounted to 346/100,000 live births. However, the 2015 MMR in Indonesia is still far from the MDG target, which targets the MMR in the range of 102/100,000 live births. The many factors related to maternal mortality in Indonesia include the quality of behavior of pregnant women who do not utilize ANC. One of the activities in integrated antenatal care involves pregnant women, husbands and families to maintain the health and nutrition of pregnant women, preparefor labor and preparedness in case of complications / complications. The purpose of this study was to describe how the husband's participation in pregnancy care was taken at the research location at the Wirosari 1 health center. This study uses a descriptive survey method, where researchers will describe the role of the husband in the care of pregnancy. The sample studied was taken using a random sampling technique of 184 pregnant women. The study was conducted in 
December 2018 - July 2019. Research data were collected using the guided interview method, which will then be processed using univariate analysis. Characteristics of respondents seen from age, education and parity. Most respondents in the age group 21-35 years were 167 respondents (91\%), with the most recent education graduating from high school as many as 60 respondents (33\%) and based on parity in the multigravida majority of 136 respondents (74\%). From the results of the study the role of the husband in pregnancy care the majority of supporting pregnant women to take care of pregnancy as many as 157 respondents (85.3\%) and the majority of pregnant women do pre gnancy care as many as 181 respondents (98.4\%). With the support of the husband to the pregnant mother in carrying out pregnancy care, the mother will be on time in carrying out pregnancy care, with the timely delivery of pregnancy care or antenatal care visits will make it ea sier for he alth workers to detect pregnancy complications early.

\section{Key words : The Role of Husband, Behavior of Pregnant Women in Pregnancy Care}

\section{PENDAHULUAN}

Millenium Development Goal's (MDGs) dalam pencapaian target di akhir tahun 2015 masih menyisakan persoalan yang secara global belum teratasi. Penyelesaian dan pencapaian target MDGs yang masih tersisa dirangkum kembali dalam Sustainable Development Goal's (SDGs). Indonesia sebagai salah satu negara yang turut serta dalam menyepakati SDGs, berkomitmen untuk menyukseskan implementasi SDGs. Sekitar $70 \%$ dari total indikator MDGs, telah berhasil dicapai oleh Indonesia. Namun, Indonesia masih memiliki sisa pekerjaan yang pencapaian targetnya masih jauh dari pencapaian target yang ditetapkan pada MDGs. Permasalahan-permasalahan yang masih tersisa di Indonesia diantaranya tingkat kemiskinan nasional, angka kematian bayi, angka kematian ibu, prevalensi gizi buruk, prevalensi HIV-AIDS serta beberapa indikator yang terkait dengan lingkungan. Indonesia sebagai salah satu negara yang turut serta menyepakati SDGs, berkomitmen untuk dapat menyukseskan implementasi SDGs dengan mengambil langkah yakni dengan menyelaraskan rencana pembangunan terhadap indikator capaian dari SDGs (Badan Pusat Statistik, 2016).

Angka Kematian Ibu (AKI) di Indonesia masih menjadi tren permasalahan kesehatan, dimana berdasarkan data SUPAS 2015 AKI berkisar 305/100.000 kelahiran hidup. Angka tersebut mengalami penurunan jika dibandingka AKI tahun 2010 sebesar 346/100.000 kelahiran hidup. Akan tetapi AKI tahun 2015 di Indonesia masih jauh dari target MDGs, yang mentargetkan AKI pada kisaran angka 102/100.000 kelahiran hidup. Untuk dapat menyelesaikan permasalahan kesehatan ibu, pemerintah mengambil terobosan- terobosan sepertipendewasaan usia pernikahan dini atau menunda kehamilan pertama sampai usia ibu minimal 18 tahun. Selain itu, pertolongan persalinan dilakukan oleh tenaga kesehatan di fasilitas pelayanan kesehatan. Dengan langkah-langkah tersebut diharapkan tahun 2030 AKI dapat mencapai angka dibawah 70/100.000 kelahiran hidup (Badan Pusat Statistik, 2016).

Berdasarkan data kematian ibu per provinsi di Indonesia, jumlah kasus kematian ibu di Provinsi Jawa Tengah pada tahun 2018 terdapat 421 kasus, mengalami penurunan dibandingkan jumlah kasus kematian ibu pada tahun 2017 sebanyak 475 kasus. Dengan demikian AKI Provinsi Jawa Tengah juga mengalami penurunan dari 109,65 per 100.000 kelahiran hidup pada tahun 2017 menjadi 88,05 per 100.000 kelahiran hidup pada tahun 2018, dengan penyebab kematian yakni hipertensi dalam kehamilan 32,97\%, gangguan metabolisme $0,87 \%$, gangguan sistem perdarahan $12,36 \%$, perdarahan $30,37 \%$, infeksi 4,34\%, lain-lain 19,09\% (Dinkes Jateng, 2018).

Banyaknya kasus ibu hamil yang mengalami komplikasi kehamilan mengakibatkan tingginya AKI salah satunya di Kabupaten Grobogan. Menurut data dari Dinas Kesehatan Kabupaten Grobogan jumlah AKI pada tahun 2017 sebanyak 18 kasus, dan pada tahun 2018 mengalami kenaikan menjadi 31 kasus, diantaranya 7 kasus perdarahan,10 kasus hipertensi dalam kehamilan dan sisanya kasus lain-lain.Salah satu faktor pendorong terjadinya AKI adalah ibu hamil yang mengalami komplikasi. Pada tahun 2017 ibu hamil dengan komplikasi kehamilan sebanyak 4.706 jiwa, sedangkan pada tahun 2018 sebanyak 4.577 jiwa. Dari data Dinas Kesehatan Kabupaten Grobogan banyaknya 
kasus komplikasi kehamilan terdeteksi di puskesmas. Pada tahun 2017 komplikasi yang menduduki peringkat pertama yakni Puskesmas Grobogan dengan kasus anemia berat sebesar 28 dan PEB sesbesar 52 jiwa, peringkat kedua Puskesmas Geyer II dengan kasus anemia berat sebesar 14 jiwa dan PEB sebesar 56 jiwa, peringkat ketiga Pusekesmas Wirosari I dengan kasus PEB sejumlah 69 jiwa. Sedangkan pada tahun 2018 kasus komplikasiyang menduduki peringkat pertama yakni Puskesmas Wirosari I dengan kasus Pre Eklamsia Berat (PEB)sebesar 78 jiwa, peringkat kedua Puskesmas Pulokulon II dengan kasus anemia berat sebesar 64 jiwa dan kasus PEB sebesar 4 jiwa serta peringkat ketiga di Puskesmas Wirosari II dengan kasus PEB sebesar 58 jiwa. Terdapat kenaikan jumlah komplikasi kehamilan pada Puskesmas Wirosari I (Dinkes Grobogan, 2018).

Banyaknya faktor yang terkait tentang kematian ibu di Indonesia diantaranya kualitas perilaku ibu hamil yang tidak memanfaatkan ANC pada pelayanan kesehatan mengakibatkan AKI di Indonesia semakin meningkat. Sedangkan cakupan K1 ideal secara nasional adalah 81,6\% dan cakupan K4 secara nasional adalah 70,4\%. Berdasarkan data tersebut, ditemukan selisih cakupan K1 dengan $\mathrm{K} 4$ secara nasional yang memperlihatkan bahwa terdapat $12 \%$ dari ibu yang menerima $\mathrm{K} 1$ ideal tidak melanjutkan ANC. Maka dari itu, rendahnya kunjungan pada ANC dapat meningkatkan komplikasi maternal dan neonatal serta kematian ibu dan anak karena adanya kehamilan yang beresiko tinggi yang tidak ditangani (Wulandari, 2016 ; Kemenkes RI, 2013).

Dari data Dinas Kesehatan Kabupaten Grobogan terdapat selisih dari K1 dengan K4 yakni pada tahun 2017 sasaran ibu hamil sebanyak 22.886 jiwa dengan K1 murni sebanyak 21.782 jiwa dan K4 sebanyak 19.907 jiwa. Sedangkan, pada tahun 2018 sasaran ibu hamil sebanyak 22.886 jiwa dengan K1 murni sebanyak 20.889 jiwa dan K4 sebanyak 19.670 jiwa. Dari data tersebut dapat dilihat bahwa banyak ibu hamil yang tidak melanjutkan kunjungan ANC setelah K1 (Dinkes Grobogan, 2018)

Guna menyukseskan program pemerintah dalam penurunan AKI, perlu pemaknaan dalam pemenuhan hak reproduksi terutama pada masa kehamilan. Ibu hamil berhak mendapatkan pelayanan kesehatan selama kehamilan, sehingga ibu hamil dapat menjalani kehamilannya dengan sehat, bersalin dengan selamat serta melahirkan bayi yang sehat dan berkualitas. Pelayanan kesehatan ibu hamil dilakukan mulai sebelum masa kehamilan dan pada saat kehamilan dengan pelayanan antenatal terpadu. Salah satu kegiatan dalam pelayanan antenatal terpadu dengan melibatkan ibu hamil, suami dan keluarga untuk menjaga kesehatan dan gizi ibu hamil, menyiapkan persalinan dan kesiagaan apabila terjadi penyulit/komplikasi (Permenkes RI, 2014).

Keterlibatan suami dan keluarga dapat mempengaruhi kondisi kesehatan ibu hamil. Kurangnya motivasi dari suami terhadap istri yang sedang hamil mengakibatkan banyak komplikasi dalam kehamilan, karena wanita yang diperhatikan dan dikasihi pasanganya selama kehamilan akan menunjukkan lebih sedikit gejala emosi dan fisik, lebih mudah melakukan penyesuaian diri selama kehamilan dan sedikit resiko komplikasi kehamilan serta persalinan. Hal ini diyakini karena ada dua kebutuhan utama yang ditunjukkan oleh wanita selama hamil yaitu menerima tanda-tanda bahwa ia dicintai dan dihargai serta kebutuhan akan penerimaan pasangannya terhadap anaknya (Rukiyah, 2014).

Beberapa peneliti menyebutkan bahwa dukungan suami dalam perawatan kehamilan akan mempengaruhi perilaku ibu hamil dalam perawatan kehamilan. Peran suami dapat meningkatkan motivasi ibu hamil tujuh kali lebih besar untuk melakukan perawatan kehamilan. Tindakan nyata yang dilakukan suami untuk mendukung ibu hamil dalam perawatan kehamilan seperti turut serta dalam pemeriksaan kehamilan, menyediakan makanan bergizi bagi ibu hamil, membantu ibu hamil untuk melakukan olahraga ringan dan aktivitas kesehariannya, menyiapkan dana dan ikut berperan aktif dalam menentukan tempat persalinan, mendampingi ibu hamil saat persalinan serta membantu ibu dalam proses laktasi (Saragih \& Nasution, 2018; Gamelia, Sistiarini \& Masfiah, 2013).

Melalui penelitian ini, peneliti ingin mendeskripsikan bagaimana peran serta suami dalam perawatan kehamilan yang diambil lokasi penelitian di Puskesmas Wirosari 1. Diharapkan dari hasil penelitian dapat memberikan kontribusi untuk meningkatkan kesejahteraan ibu selama masa kehamilan. 


\section{METODE}

Penelitian ini menggunakan metode survei deskriptif, dimana peneliti akan mendeskripsikan peran suami dalam perawatan kehamilan. Populasi penelitian menggunakan ibu hamil yang tercatat pada register ibu hamil di Puskesmas Wirosari I sebanyak 340 ibu hamil. Selanjutnya, sampel yang diteliti diambil menggunakan teknik random sampling sejumlah 184 ibu hamil. Penelitian dilaksanakan pada bulan Desember 2018 - Juli 2019.

Data yang digunakan dalam penelitian berupa data primer yang diperoleh secara langsung melalui wawancara terpimpin dengan ibu hamil yang berpedoman pada kuesioner yang telah disusun sebelumnya. Selain data primer, peneliti juga menggunakan data sekunder berupa data register ibu hamil Puskesmas Wirosari I dan data kesehatan ibu dan anak yang berasal dari Dinas Kesehatan Kabupaten Grobogan. Data primer yang diperoleh selanjutnya dilakukan analisis menggunakan analisis univariat, dimana datadata yang didapat disajikan dalam bentuk tabel distribusi frekuensi.

\section{HASIL}

Penelitian ini dilakukan di Puskesmas Wirosari I Kecamatan Wirosari Kabupaten Grobogan. Secara geografis Kecamatan Wirosari terletak di bagian timur Kabupaten Grobogan dengan jarak $20 \mathrm{~km}$ dari ibu kota Kabupaten dan luas 15.430 ha, dengan batasbatas wilayah adalah utara: Kabupaten Pati, Barat: Kecamatan Tawangharjo dan Kabupaten Pati, Timur: Kecamatan Ngaringan dan Kabupaten Blora, Selatan: Kecamatan Pulokulon dan Kradenan .Kecamatan Wirosari terdiri dari 14 desa dengan jumlah penduduk 125.876 jiwa.

Puskesmas Wirosari I merupakan salah satu fasilitas pelayanan kesehatan di daerah tersebut.Jumlah tenaga kesehatan di Puskesmas Wirosari I ada 95 orang, jumlah bidan ada 20 orang. Jenis pelayanan di Puskesmas ini ada 5 program salah satunya yakni program Kesehatan Ibu dan Anak (KIA) melayani pemeriksaan kehamilan, Keluarga Berencana (KB), imunisasi, persalinan 24 jam, pemeriksaan ibu nifas dan pengobatan anak. Pelayanan KIA dilakukan setiap hari Rabu dan Kamis dari pukul 08.00-sampai selesai. Terletak di Jalan Kusuma Bangsa, Kunden, Wirosasi, Kabupaten Grobogan.

B. Karakteris tik Responden Penelitian

A. Gambaran Lokasi Penelitian

Tabel 1. Karakte ristik Ibu Hamil di Puskesmas Wirosari I Tahun 2019

\begin{tabular}{clcc}
\hline No & \multicolumn{1}{c}{ Variabel } & N & \% \\
\hline 1 & Usia & & \\
& $<20$ tahun & 8 & 4 \\
& $21-35$ tahun & 167 & 91 \\
& 35 tahun & 9 & 5 \\
2 & Pendidikan Te rakhir & 39 & 21 \\
& Sekolah Dasar (SD) & 54 & 29 \\
& Sekolah Menengah Pertama (SMP) & 60 & 33 \\
& Sekolah Menengah Atas (SMA) & 31 & 17 \\
& Perguruan Tinggi (PT) & & \\
Paritas & 46 & 25 \\
& Primigravida & 136 & 74 \\
& Multigravida & 2 & 1 \\
\hline & Grandemultigravida & $\mathbf{1 8 4}$ & $\mathbf{1 0 0}$ \\
\hline
\end{tabular}

Sumber data : Data Primer, 2019

Berdasarkan tabel 1. diketahui karakteristik responden dilihat dari usia, pendidikan terakhir dan paritas. Karakteristik responden berdasarkan usia dapat diketahui bahwa sebagian besar 91\% (167 responden) termasuk dalam kelompok usia 21-35 tahun. Karakteristik responden dilihat dari pendidikan terakhir sebagian besar $33 \%$ (60 responden) lulusan Sekolah Menengah Atas (SMA) dan berdasarkan paritas sebagian besar 74\% (136 responden) termasuk kelompok multigravida.

C. Analis a Univariat

1. Peran Suami dalam Perawatan Kehamilan 
Tabel 2. Distribusi Frekuensi Peran Suami dalam Perawatan Kehamilan di Puskesmas Wirosari I, Tahun 2019

\begin{tabular}{clcc}
\hline No & Variabel & N & \% \\
\hline 1 & Suami yang mendukung & 180 & $97,8 \%$ \\
2 & Suami yang tidak mendukung & 4 & $2,2 \%$ \\
\hline & Total & $\mathbf{1 8 4}$ & $\mathbf{1 0 0 \%}$ \\
\hline
\end{tabular}

Sumber data : Data Primer, 2019

Berdasarkan Tabel 2. menunjukkan bahwa mayoritas 97,8\% (180 responden) menyatakan suami memberikan dukungan kepada ibu hamil dalam perawatan

Tabel 3. Distribusi Frekuensi Perawatan Kehamilan di Puskesmas Wirosari I, Tahun 2019

\begin{tabular}{clcc}
\hline No & Variabel & $\mathbf{N}$ & \% \\
\hline 1 & $\begin{array}{l}\text { Melakukan perawatan kehamilan } \\
\text { Tidak melakukan perawatan } \\
2\end{array}$ & 181 & $98,4 \%$ \\
kehamilan & 3 & $1,6 \%$ \\
\hline & Total & $\mathbf{1 8 4}$ & $\mathbf{1 0 0 \%}$ \\
\hline
\end{tabular}

Sumber data : Data Primer, 2019

Tabel 3. menunjukkan bahwa responden (ibu hamil) sebagian besar $98,4 \%$ (181 responden) melakukan perawatan kehamilan. Artinya bahwa ibu hamil di Puskesmas Wirosari 1 memiliki perilaku baik dalam perawatan kehamilannya, hanya $1,6 \%$ (3 responden) yang tidak melakukan perawatan kehamilan dengan baik.

\section{PEMBAHASAN}

\section{A. Karakte ris tik Responden}

Berdasarkan Tabel 1. diketahui karakteristik responden (ibu hamil) berdasarkan usia, pendidikan terakhir dan paritas. Berdasarkan usia ibu, sebagian besar responden $91 \%$ merupakan kelompok usia 2135 tahun dan sebanyak 4\% kelompok usia $<20$ tahun. Menurut Prihandini, Pujiastuti \& Hastuti (2016), bahwa seorang ibu hamil termasuk dalam kelompok resiko jika usia $<20$ tahun atau > 35 tahun. Rentang usia seorang ibu dikatakan sehat dalam proses reproduksi pada usia 20 - 35 tahun. Pada rentang usia 20 - 35 tahun, fisik seorang wanita telah mencapai puncak pertumbuhannya, sehingga aman jika terjadi proses kehamilan. Sedangkan, usia $<20$ tahun memiliki resiko tinggi bagi seorang wanita untuk mengalami kehamilan karena pada usia tersebut tubuh dianggap belum matang baik secara fisik, emosional dan mental. Dan pada usia > 35 tahun fungsi reproduksi seorang wanita sudah mengalami penurunan, sehingga lebih beresiko kehamilannya. Sedangkan 2,2 \% ibu hamil menyebutkan tidak mendapatkan dukungan suami.

\section{Perawatan Kehamilan}

dalam menghadapi komplikasi pada kehamilan, persalinan ataupun masa nifas.

Karakteristik ibu hamil dilihat dari pendidikan terakhir diketahui sebagian besar $33 \%$ merupakan tamatan SMA dan sebagian kecil 17\% tamatan Perguruan Tinggi. Menurut Ningsih (2017) menyebutkan bahwa tingkat pendidikan seorang ibu akan mempengaruhi penerimaan informasi, sehingga akan berpengaruh pada tingkat pengetahuannya. Tingkat pendidikan yang rendah akan lebih sulit bagi seorang ibu untuk mempersepsikan dan menghambat perkembangan sikap ibu terhadap nilai-nilai yang baru.

Karakteristik ibu hamil berdasarkan paritas sebagian besar $74 \%$ kelompok multigravida sedangkan $1 \%$ adalah grandemultigravida. Jarak ideal seorang wanita untuk mengalami kehamilan sehat antara 2-4 tahun. Paritas dapat mempengaruhi kondisi psikologis ibu hamil terutama pada kehamilan Trimester III. Seorang primigravida merasakan ketakutan lebih tinggi karena belum memiliki pengalaman dalam proses persalinan dibandingkan pada multigravida (Rinata \& Andayani, 2018).

\section{B. Peran Suami dalam Perawatan Kehamilan}

Tabel 2. menunjukkan bahwa mayoritas 97,8\% suami memberikan dukungan kepada ibu hamil dalam perawatan kehamilannya. Sedangkan 2,2 \% ibu hamil menyebutkan tidak mendapatkan dukungan suami. Berdasarkan jawaban responden, suami 
yang tidak memberikan dukungan penuh dikarenakan beberapa faktor, seperti suami bekerja diluar kota, multigravida (ibu dianggap telah memiliki pengalaman pada kehamilan sebelumnya), faktor ekonomi dan kurangnya pengetahuan suami tentang pentingnya perawatan kehamilan. Menurut Hasanah \& Fitriyah (2018), tingkat pengetahuan suami tentang perawatan kehamilan diperoleh dari lingkungan sekitar. Suami yang memiliki tingkat pengetahuan yang baik akan memberikan respon positif kepada ibu hamil dalam perawatan kehamilannya. Nilai-nilai pengetahuan yang didapatkan terkait perawatan kehamilan dijadikan pedoman dalam pengambilan keputusan terkait proses kehamilan istri, seperti pemilihan tempat persalinan, penolong persalinan, kecukupan asupan gizi ibu hamil dan keteraturan ibu hamil melakukan pemeriksaan kehamilan (Ante Natal Care/ANC).

Hasanah \& Fitriyah (2018), sebagian besar suami yang memiliki perilaku cukup baik kepada istri selama kehamilan ditunjukkan dengan melakukan perawatan kehamilan seperti turut mendampingi istri dalam pemeriksaan kehamilan, mengajak istri jalanjalan, tidak merokok disekitar istri serta membantu aktivitas keseharian istri. Terbentuknya perilaku dimulai dari domain kognitif seseorang terhadap stimulus dari luar. Perilaku suami dalam berpartisipasi melakukan perawatan kehamilan terhadap istri merupakan bentuk perilaku kesehatan dimana tindakan yang dilakukan berkaitan dengan pemeliharaan dan peningkatan kesehatan ibu dan janin.

Suami adalah orang yang paling penting bagi seorang wanita hamil. Karena perhatian dan kasih sayang oleh pasangan selama kehamilan akan menunjukkan lebih sedikit gejala emosi dan fisik, lebih mudah melakukan penyesuaian diri selama kehamilan serta sedikit resiko selama kehamilan dan persalinan. Hal ini diyakini karena ada dua kebutuhan utama yang ditunjukkan wanita selama hamil yakni menerima tanda-tanda bahwa ia dicintai dan dihargai serta kebutuhan akan penerimaan pasangannya terhadap anaknya (Rukiah, 2014).

Gamelia, Sistiarani \& Masfiah (2013) dalam penelitiannya menyebutkan terdapat korelasi yang signifikan antara sikap dan perilaku perawatan kehamilan. Dukungan suami yang baik akan memberikan motivasi yang baik bagi ibu hamil untuk memeriksakan kehamilannya. Keterlibatan suami sejak awal kehamilan sampai dengan persalinan dan masa nifas akan meningkatkan perilaku perawatan ibu hamil, sehingga menentukan keberhasilan ibu dalam masa kehamilan sampai dengan proses persalinan. Peran suami merupakan variabel yang paling berpengaruh terhadap perilaku perawatan kehamilan ibu. Dalam masyarakat patriarkhi suami berpengaruh terhadap pengambilan keputusan dalam keluarga. Keterlibatan suami dalam perawatan antenatal menunjukkan bahwa dukungan emosional, instrumental dan informasi sangat berpengaruh terhadap kesehatan ibu hamil.

\section{Pe rawatan Kehamilan}

Tabel 3. menunjukkan bahwa responden (ibu hamil) sebagian besar 98,4\% (181 responden) melakukan perawatan kehamilan. Responden yang melakukan perawatan kehamilan ataupun tidak melakukan perawatan kehamilan dapat dilihat dari hasil pemeriksaan kehamilan (antenatal care) tepat waktu (trimester I: 1x, trimester II: $1 \mathrm{x}$, trimester III: $2 \mathrm{x}$ ), dengan hasil mayoritas ibu hamil melakukan perawatan kehamilan.

Berdasarkan jawaban responden, terdapat ibu hamil yang tidak melakukan melakukan pearawatan kehamilan ataupun kunjungan antenatal care dengan alasan karena sudah pernah mengalami kehamilan lebih dari 3 kali dan tidak ada yang mengantarkan periksa ke puskesmas. Perawatan kehamilan merupakan pelayanan kesehatan oleh tenaga kesehatan untuk ibu selama masa kehamilannya. Dilaksanakan sesuai dengan standar pelayanan antenatal care yang ditetapkan. Dalam perawatan kehamilan dilakukan scrining yaitu program yang bersifat berkesinambungan selama kehamilan, persalinan, kelahiran, dan nifas yang terdiri atas edukasi, deteksi dini, pencegahan, pengobatan, rehabilitas, yang bertujuan untuk memberikan rasa aman dan nyaman sehingga ibu mampu merawat bayi dengan baik (DepKes, 2010).

Beberapa peneliti menyebutkan dalam hasil penelitiannya, bahwa ibu hamil lebih banyak melakukan kunjungan ANC lebih banyak karena dukungan dari suami. Hal ini terlihat dari ibu hamil yang melakukan kunjungan $\mathrm{ANC} \pm 4$ kali dengan demikian dapat dikatakan ibu hamil melakukan kunjungan ANC dengan baik. Ibu hamil dengan dukungan keluarga juga akan lebih termotivasi mengikuti kelas hamil 
dibandingkan ibu hamil yang mengikuti kelas hamil dengan kesadaran diri (Pertiwi dkk, 2017; Imroatul dkk, 2018).

Sedangkan ibu hamil yang tidak melakukan perawatan kehamilan seringkali dikarenakan alasan fasilitas kesehatan yang kurang memadai, jarak dari pelayanan kesehatan, tidak adanya yang mengantar periksa, jam periksa bentrok dengan jam kerja, biaya pemeriksaan yang mahal bagi ekonomi rendah, ibu hamil yang sudah pernah mengalami hamil lebih dari 3 kali kurang mengkhawatirkan kondisi kehamilannya dan kurangnya pengetahuan tentang pentingnya perawatan kehamilan (Imroatul, dkk.,2018)

\section{SIMPULAN DAN SARAN}

\section{A. Simpulan}

1. Karakteristik responden dilihat dari usia, pendidikan dan paritas. Sebagian besar responden kelompok usia 21-35 tahun sebanyak 167 responden (91\%), dengan pendidikan terakhir mayoritas tamat SMA sebanyak 60 responden (33\%) dan berdasarkan paritas mayoritas multigravida sebanyak 136 responden (74\%);

2. Hasil penelitian ditemukan bahwa sebagian besar suami mendukung ibu hamil untuk melakukan perawatan kehamilan sebanyak 157 responden $(85,3 \%)$;

3. Hasil penelitian ditemukan bahwa sebagian besar responden (ibu hamil) melakukan perawatan kehamilan sebanyak 181 responden $(98,4 \%)$.

\section{B. Saran}

1. Penting bagi ibu hamil untuk dapat melakukan perawatan kehamilan, baik pemeriksaan kehamilan dan perawatan diri sehingga kesehatan ibu selama kehamilan dapat terjaga serta menghasilkan anak yang sehat sewaktu ibu melahirkan;

2. Peran serta suami dan keluarga sangat dibutuhkan bagi ibu hamil. Hal tersebut berguna untuk meningkatkan motivasi diri ibu hamil untuk melakukan perawatan kehamilan. Bentuk dukungan tersebut dapat berupa dukungan fisik dan psikologis.

3. Tenaga kesehatan khususnya bidan sebagai pendamping ibu hamil perlu meningkatkan mutu pelayanan dalam implementasi antenatal care, khususnya dalam konseling dan pemberian edukasi. Hal tersebut dimaksudkan untuk mengidentifikasi psikologis ibu hamil, sehingga keseahatan ibu hamil terjamin baik fisik maupun psikologis.

\section{DAFTAR PUSTAKA}

1. Badan Pusat Statistik. 2016. Kajian Indikator Lintas Sektor : Potret Awal Tujuan Pembangunan Berkelanjutan (Sustainable Development Goals) di Indonesia. Jakarta : Badan Pusat Statistik Indonesia

2. BKKBN, BPS, Kementerian Kesehatan \& USAID. 2018. Survei Demografi dan Kesehatan Indonesia 2017. Jakarta : BKKBN

3. Departemen Kesehatan Republik Indonesia. 2010. Pegangan Fasilitas Kelas Ibu Hamil. Jakarta: Departemen Kesehatan RI

4. Dinas Kesehatan Kabupaten Grobogan. 2018. Profil Kesehatan Kabupaten Grobogan. Grobogan : Dinas Kesehatan Kabupaten Grobogan

5. Dinas Kesehatan Provinsi Jawa Tengah. 2018. Profil Kesehatan Provinsi Jawa Tengah. Semarang : Dinas Kesehatan Provinsi Jawa Tengah

6. Gamelia, E., Sistiarani, C. \& Masfiah, S. 2013. Determinan Perilaku Perawatan Kehamilan. Jurnal Kesehatan Masyarakat Nasional. Volume 8. Nomor 3. Oktober 2013

7. Hasanah, I. \& Fitriyah, N. 2018. Peran Suami dalam Perawatan Kehamilan Istri di Kelurahan Mulyorejo. Jurnal Biometrika dan Kependudukan. Volume 7. Nomor 2. Desember 2018

8. Imroatul H, dkk. 2018. Peran Suami dalam Perawatan Kehamilan Istri di Kelurahan Mulyorejo. https://e-journal.unair.ac.id (di akses tanggal 24 Maret 2019)

9. Kementerian Kesehatan RI. 2014. Peraturan Menteri Kesehatan Republik Indonesia Nomor 97 Tahun 2014 tentang Pelayanan Kesehatan Masa Sebelum Hamil, Masa Hamil, Persalinan dan Masa Sesudah Melahirkan, Penyelenggaraan Pelayanan Kontrasepsi serta Pelayanan Kesehatan Seksual. Jakarta : Kementerian Kesehatan RI

10. Kementerian Kesehatan RI. 2019. Laporan Nasional RISKESDAS 2018. Jakarta : Badan Penelitian dan Pengembangan Kesehatan 
11. Narulita Sari Rury. 2014. Hubungan antara Dukungan Suami dengan Ketepatan Jadwal Kunjungan Antenatal Care pada Ibu Hamil Trimester III. Desember 2014

12. Ningsih Eka Sarofah. 2017. Hubungan Tingkat Pendidikan Ibu Hamil Trimester III dengan Keteraturan Kunjungan ANC. Jurnal Midpro. Volume 9. Nomor 2. Desember 2017

13. Notoatmodjo Soekidjo. 2010. Metodologi Penelitian Kesehatan. Edisi Revisi. Jakarta : Rineka Cipta

14. Pertiwi dkk. 2014. Hubungan Dukungan Suami Dengan Kecenderungan Depresi Pada Ibu Hamil di Puskesmas Manggarau. http://www.stikessumatera.ac.id (diakses tanggal 5 juli 2019)

15. Prihandini, S.R., Pujiastuti, W. \& Hastuti, T.P. 2016. Usia Reproduksi Tidak Sehat dan Jarak Kehamilan yang Terlalu Dekat Meningkatkan Kejadian Abortus di Rumah Sakit Tentara Dokter Soedjono Magelang .
Jurnal Kebidanan. Volume 5. Nomor 9. April 2016

16. Rinata, E. \& Andayani, G.A. 2018. Karakteristik Ibu (Usia, Paritas, Pendidikan) dan Dukungan Keluarga dengan Kecemasan Ibu Hamil Trimester III. Medisains : Jurnal Ilmiah ilmu-Ilmu Kesehatan. Volume 16. Nomor 1. April 2018

17. Rukiah AY dkk. 2014. Asuhan Kebidanan Kehamilan Berbasis Kompetensi. Jakarta:Trans Info Media

18. Saryono. 2008. Metodologi Penelitian Kesehatan Penuntun Praktis Bagi Pemula. Cetakan Pertama. Jogjakarta : Mitra Cendekia Press

19. Walyani, Elisabeth S. 2014. Asuhan Kebidanan Kegawatdaruratan Maternal dan Neonatal. Pustaka Baru Perss

20. Wulandari E, 2016. Faktor-faktor yang Berhubungan dengan Pemeriksaan Antenatal Care di Wilayah Kerja Puskesmas Pisangan. 